\title{
Webquest Technologies as Learning Motivation
}

\author{
${ }^{1}$ Iskander Yarmakeev, ${ }^{2}$ Nelly Valiakhmetova, ${ }^{3}$ Rimma Akhmadullina, ${ }^{4}$ Guseynova Terane \\ 1-4 Kazan Federal University \\ Email:nellyv1975@mail.ru
}

Received: 20 ${ }^{\text {th }}$ August 2019, Accepted: 30 ${ }^{\text {th }}$ September 2019, Published: $31^{\text {st }}$ October 2019

\begin{abstract}
The study is devoted to the urgent problem of finding effective means of forming the learning motivation of students who are future teachers.

The quality of education is largely determined by the level of formation of learning motivation. In the conditions of the innovative nature of modern education, the search for effective pedagogical tools and technologies to stimulate the development of learning motives of students remains as the permanent task.

According to the authors, a web-quest technology that combines the elements of the case method, problem-based learning, design, research, and game methods and often based on the use of information and communication technologies has significant potential in solving this problem.

The purpose of the paper is to reveal the possibility of the formation of learning motivation through WebQuest technology in the study of pedagogical disciplines.

The paper describes the results for the diagnosis of learning motivation in students according to the criteria of a conscious attitude to the problems of education and emotional perception of various activities in changing circumstances. The results for a comparative analysis of the types of educational web quests and educational motives are also presented by the example of studying the discipline "Education in the Republic of Tatarstan".

The data obtained in this study can be recommended to university teachers to organize the educational process in order to form the learning motivation of students.
\end{abstract}

\author{
Keywords \\ Student Learning Motivation, Formation, Web Quest Technology, Potential.
}

\section{Introduction}

The problem of the formation of learning motivation does not cease to be in the centre of attention of studies in the field of psychology and pedagogy. Its actualization is associated with objective processes taking place in society and in the field of domestic education, among which the most significant processes from our point of view can be noted. First, an appeal to the student-centred educational paradigm has provided great opportunities for the development of individual psychological characteristics of the personality of students. The personality-oriented approach focuses on a developed system of internal learning motives: cognitive, semantic, goal-setting, and self-development motives. This approach is simultaneously based on them and stimulates their development.

The task of developing learning motivation is also being updated in connection with the implementation of the competency-based approach in the system of higher professional education [1], [2]. In accordance with it, the competences of specialists are determined by their personal qualities, abilities and characteristics of motivation, which must be formed at the stage of professional training.

The second important reason for the relevance of the issue is the specifics of the current young generation. It is defined as "digital" and is distinguished by a number of socio-psychological characteristics manifested in its behaviour and thinking. The main problem that arose in education in connection with this phenomenon is that the way of social communication between generations has changed, namely: the type of sociocultural inheritance through education. The youth united by information networks has developed a community of experience that the elders never had, and the older generation will never see a repeat of their experience in the life of young people. And thus, the idea of direct transfer of known experience from one generation to another, within the framework of traditional education, contradicts the new one tool for communication between generations [3].

Under these conditions, the educational process was faced with the need to ensure generation by students their personal knowledge and their own image of the world [4]. And this, in our opinion, can be realized through the development of internal educational and cognitive motives among students, which will create the basis for independent mastery of the necessary information and its transformation into meaningful personal knowledge.

The indicated realities stimulated innovations in the field of goals and content of education, and, in particular, the search and widespread introduction of innovative forms and technologies of education. Particular attention is paid to interactive technologies. They contribute to the development of students' competencies, creative abilities and initiatives in the field of knowledge acquisition. In this case, as the researchers point out, a completely new group of motives arises: cognitive motives for an unselfish search for truth, when interest in learning arises in the process of intellectual learning activity based on the search and solution of a problem, and as a result there is an internal interest in mastering knowledge [5].

In this context, great importance is attached to interactive technologies based on the use of Internet resources [6], [7]. Among them, WebQuest technology has significant potential for generating positive learning motivation. It is this 
which provides students with the usual hypertext mode for delivering educational information, helping to increase motivation, stimulate cognitive activity and develop critical thinking [8].

There is a fair amount of research on the importance of using WebQuest in training. Research by G. Gorghiu [9] showed that this technology serves as a way to integrate the Internet into learning, and one of its greatest achievements is the positive motivation of students. March T. notes that using WebQuest in students' work on a project helps them to establish deeper substantive connections, stimulates cognitive interest and increases motivation for acquiring knowledge and working together [10]. In the works by Aina S.A. and Sofowora A.O., WebQuest's role as a motivating creative tool when teaching students was investigated. [11]

However, despite the results of studies that evaluate the impact of WebQuest technology on the formation of learning motivation as positive, there are practically no studies on the potential of pedagogical disciplines on the use of this technology. This circumstance made it possible to formulate the purpose of this study: to reveal the possibilities of the formation of learning motivation through WebQuest technology in the study of pedagogical disciplines.

\section{Materials and Methods}

The methodological basis of this study unites an activity-based approach to the study of motivation; concepts of motivation for educational activities; and educational web quest concept.

The main research methods were: analysis of scientific and theoretical sources, a survey, comparative method, and structurally meaningful analysis.

Consider some theoretical provisions regarding the learning motivation of students in order to identify the possibilities of its formation through WebQuest technology in the study of pedagogical disciplines.

From our point of view, the most successful is the definition of learning motivation as a special type, due to the specifics of educational activity, while the main motive in its structure is cognitive interest [12]. In our work, we rely on the classification of teaching motives by A. K. Markova, who distinguishes two groups of motives: cognitive (aimed at the process and methods of cognition) and social [13].

The process of learning motivation formation by students is quite complicated, since it is influenced by many factors: organizational (construction of the educational process, material and technical conditions, information and methodological support, and a system for assessing learning outcomes); psychological (personality characteristics, relationships in the student team); and pedagogical (qualifications of teachers, especially their position and style of interaction with students, educational technologies, the specifics of the subject learnt).

The motivational sphere is mobile and changeable. The process of motivation formation needs to be managed, otherwise, its level may decrease and motives will disappear.

At different stages of training, an alternation of professional and educational motives takes place, the structure of the motives of the educational activity itself changes, which form a single system with values and goals [14].

Modern researchers believe that increasing academic performance is directly related to the level of motivation of students' educational activities, and this, in turn, depends on the understanding of the personal meanings of the knowledge gained.

In this context, WebQuest technology provides great opportunities to take into account the individual psychological characteristics of a person and helps to reduce the contradictions between the lecture and seminar form of training and students' independent cognitive activity when they get the opportunity to create their own development trajectory. That is, it actually brings together the external and internal sides of motivation.

\section{Results}

At the first stage of the practical part of the work, we studied the educational motives of the 3rd year students of Kazan Federal University, which are undergraduates studying in the field of "Vocational Training", the training track "Interior Design" (sample - 31 people). The processing of empirical material was carried out on the basis of a diagnostic technique for motivating vocational training [15].

The questionnaire consisted of 6 questions and 44 allegations. The Likert scale was used, according to which each statement was evaluated by the respondent from 1 (surely "not") to 5 (surely "yes") points. The first 24 questions were aimed at identifying the level of conscious attitude to the problems of learning, and the next 20 questions were aimed at determining the emotional perception of various types of activity in changing circumstances.

The results were evaluated on four scales. Each of them corresponded to its level of learning motivation - low, medium, normal or high.

The low level is characterized by an indifferent attitude to the educational process. The sense of learning is not recognized. Cognitive activity is manifested as the need to fulfil the requirements of a teacher without personal interest in that.

Medium level: the manifestation of cognitive activity is random and more often associated with interest in the result. Students with a medium level of motivation for learning are more attracted to leisure than educational activities.

The normal level of motivation is manifested in focusing on educational and professional activities, on the development of self-education and self-knowledge; the desire to express their own position, achieve significant specific results in learning activities.

The high level of motivation for learning is distinguished by the desire to acquire new knowledge and obtain satisfaction from the process of cognition, and focusing on self-development. 
According to the results of the data obtained, it can be said that for most students (48.4\%) the average level of motivation for learning is characteristic (see table 1). Students with a low level of motivation for teaching make up $6.4 \%$, normal $-32.2 \%$, high $-13 \%$ of the total number of respondents.

\begin{tabular}{|c|c|}
\hline Motivation level & Number of students with a given level of motivation \\
\hline I (low) level & $6.4 \%(2)$ \\
\hline II (medium) level & $48.4 \%(15)$ \\
\hline III (normal) level & $32.2 \%(10)$ \\
\hline IV (high) level & $13 \%(4)$ \\
\hline
\end{tabular}

Table 1: The Results of the Distribution of Students by Levels of Learning Motivation

The obtained results of the learning motivation levels are graphically presented in the form of the following diagram:
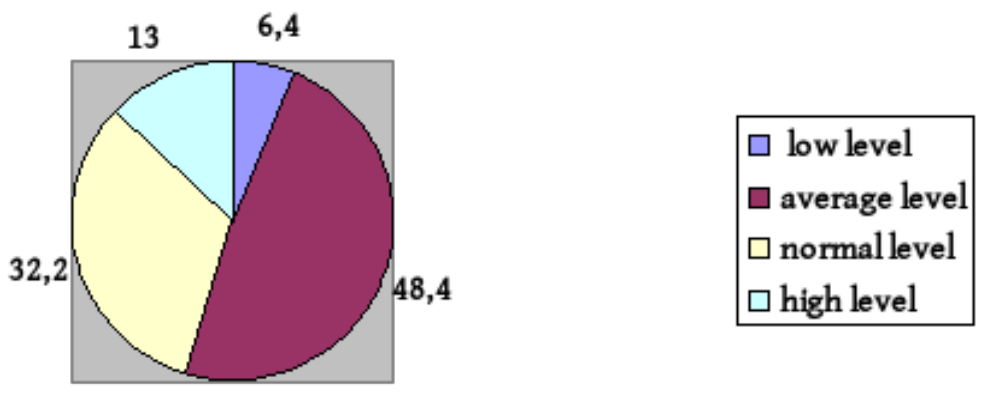

Fig. 1: Distribution of Students by their Level of Motivation

Interviewed students were of 3rd year study, namely, at this stage, there is a decrease in the motivation of learning, and the dominant motives change [16].

At the next stage of our study, we streamlined the typology of educational web quests based on the study of existing classifications [17], [18].

Structurally-substantive analysis of the discipline "Education in the Republic of Tatarstan" made it possible to identify the capabilities of this technology in the formation of positive learning motivation for future teachers. The results are presented in Table 2 .

\begin{tabular}{|l|l|l|l|}
\hline $\begin{array}{c}\text { Item } \\
\text { no. }\end{array}$ & $\begin{array}{l}\text { Examples of topics (module) of the } \\
\text { discipline }\end{array}$ & \multicolumn{1}{|c|}{ Web quest typology } & \multicolumn{1}{c|}{ Learning motive formed } \\
\hline 1. & $\begin{array}{l}\text { Writing in ancient Turkic tribes. } \\
\text { The emergence of Tatar writing. }\end{array}$ & $\begin{array}{l}\text { Short-term, mono-subject, cyclic; type } \\
\text { of assignment: writing an interactive } \\
\text { story; scientific research - the study of } \\
\text { various phenomena, discoveries, facts } \\
\text { based on unique on-line sources }\end{array}$ & $\begin{array}{l}\text { the motive of cognitive } \\
\text { interest and creative self- } \\
\text { realization }\end{array}$ \\
\hline 2. & $\begin{array}{l}\text { The emergence and development } \\
\text { of Tatar enlightenment }\end{array}$ & $\begin{array}{l}\text { Short-term, mono-subject, assault; job } \\
\text { type: an on-line interview with a virtual } \\
\text { character }\end{array}$ & $\begin{array}{l}\text { motive of cognitive } \\
\text { interest, and } \\
\text { communicative motive }\end{array}$ \\
\hline 3. & $\begin{array}{l}\text { Kazan University in the Volga } \\
\text { region spiritual culture }\end{array}$ & $\begin{array}{l}\text { Short-term, interdisciplinary, linear; } \\
\text { type of task: creating a microworld, with } \\
\text { the ability to move with the help of } \\
\text { hyperlinks, simulating physical space }\end{array}$ & $\begin{array}{l}\text { the motive of cognitive } \\
\text { interest }\end{array}$ \\
\hline 4. & Traditions of Tatar folk pedagogy & $\begin{array}{l}\text { Short-term, mono-subject, assault; type } \\
\text { of task: compilation - a transformation } \\
\text { of the format of information received } \\
\text { from different sources (creating a book } \\
\text { of recipes, a virtual exhibition, time } \\
\text { capsule, culture capsule, etc.). }\end{array}$ & $\begin{array}{l}\text { social and cognitive } \\
\text { motive, creative self- } \\
\text { realization }\end{array}$ \\
\hline 5. & $\begin{array}{l}\text { The development of national } \\
\text { education in Tatarstan }\end{array}$ & $\begin{array}{l}\text { Short-term, mono-subject, ring; type of } \\
\text { task: journalistic investigation - } \\
\text { objective presentation of information } \\
\text { (separation of opinions and facts) }\end{array}$ & $\begin{array}{l}\text { social and cognitive } \\
\text { motive }\end{array}$ \\
\hline
\end{tabular}




\begin{tabular}{|l|l|l|l|}
\hline 6 & $\begin{array}{l}\text { The educational potential of } \\
\text { cultural and historical monuments } \\
\text { of Tatarstan }\end{array}$ & $\begin{array}{l}\text { Short-term, interdisciplinary, linear; } \\
\text { type of task: creative task - creative } \\
\text { work in a particular genre - creating a } \\
\text { play, poem, video clip, song }\end{array}$ & $\begin{array}{l}\text { the motive for achieving } \\
\text { and avoiding failures, the } \\
\text { motive for creative self- } \\
\text { realization }\end{array}$ \\
\hline 7. & $\begin{array}{l}\text { Modern trends and prospects for } \\
\text { the development of education in } \\
\text { Tatarstan }\end{array}$ & $\begin{array}{l}\text { Short-term, mono-subject, assault; type } \\
\text { of task: detective story, puzzle, } \\
\text { mysterious story - conclusions based on } \\
\text { conflicting facts; consensus-building - } \\
\text { working out a solution to an acute } \\
\text { problem; assessment - the rationale for a } \\
\text { certain point of view. }\end{array}$ & $\begin{array}{l}\text { the motive of cognitive } \\
\text { need, motive of } \\
\text { achievement and } \\
\text { avoidance of failure }\end{array}$ \\
\hline
\end{tabular}

Table 2: Comparison of Types of Educational Web Quests and Educational Motives by the Example of Studying the Discipline "Education in the Republic of Tatarstan"

\section{Discussion}

A variety of concepts and views on understanding the essence of the motivation of educational activity and the conditions for its formation sometimes complicates the use of scientific data for practical application. An example is a difference in the views of Russian and foreign researchers on key factors ensuring the development of learning motivation. So, for example, A.A. Verbitsky singles out problematicity, an optimal level of difficulty, an individual's activity, a consistent generalization of assimilated educational material, and progress from abstract to concrete as key learning conditions [19]. Foreign authors assign the main role for the development of internal motives of learning to meet the needs of students in autonomy from the teacher, and their awareness of their own competence [20].

On the other hand, despite the obvious attractiveness and effectiveness of WebQuest technology for the formation of learning motivation, researchers have identified a number of problems regarding both the conditions under which this technology is used and the understanding of its essence by the pedagogical community. Obstacles to their effective use may include lack of clear instructions and reliable links to web resources, tasks that are too complex, and the ability to get distracted by other interesting and attractive websites [21]. Also, a decrease in motivation and a feeling of increased difficulty can cause technical problems [22].

It is likely that a subjective factor that reduces the effectiveness of using the technology under discussion can be attributed to the insufficient qualification of the teacher, who does not always recognize the specifics of WebQuest.

\section{Summary}

The results of the study allow us to draw the following conclusions: 1) the organization of the educational process and the specifics of the content of a discipline play an important role in the formation of motivation on its learning; 2) the disclosure of the WebQuest technology potential, combining elements of the problem and game methods, is possible on a basis of comparison of the educational quest types and the motives of educational activity.

\section{Conclusions}

The results of this work prove that the use of WebQuest technology can contribute to the disclosure of the emotionalvolitional sphere, and the activation of independent cognitive activity.

\section{Acknowledgements}

The work is carried out according to the Russian Government's Program of Competitive Growth of Kazan Federal University

\section{References}

[1] R. Zaripova, L. Salekhova, S. Grigoriev, K. Grigorieva, An ICT-mediated constructivist approach in increasing academic motivation VIA CLIL. Journal of Fundamental and Applied Science. 2018. Vol.10. №4S. pp.1112-1221.

[2] L.M. Sirazieva, R.A. Fakhrutdinova, R. R. Fakhrutdinov, Methods of assessing students' self-regulated learning skills. Ad Alta-Journal of Interdisciplinary Research, 2017. pp. 168-170.

[3] A.A. Verbitsky, "Digital Generation": problems of education. Professional education. Stolitsa. Number 7. 2016 , pp. $10-13$.

[4] G.L. Ilyin, Projective education and the reformation of science. M., 1993.216 p.

[5] M. Lukoyanova, A. Khusainova, The improvement of the information technology training efficiency for students of humanities, INTED 2016: 10th international technology, education and development conference, pp.7459-7465, 2016.

[6] M. Lukoyanova, A. Khusainova, Implementing project technology in teaching master students majoring in "Education", INTED 2018: 10th international technology, education and development conference. Proceedings. pp. 4358-4364, 2018.

[7] E.Yu. Grudzinskaya, V.I. Petkov, Modern approaches to teaching training courses. Nizhny Novgorod, 2011.53 p. [8] [8] L. Averkieva, Y. Chayka, S. Glushkov, Web quest as a tool for increasing students' motivation and critical thinking development. Procedia - Social and Behavioral Sciences. Procedia - Social and Behavioral Sciences 206 (2015) $137-140$. 
[9] G. Gorghiu, L. Gorghiu, V. Gonzalez, A. De La Santa. Webquest in the Classroom - Analysis of its Impact, 3rd International Conference on Multimedia and Information \& Communication Technologies in Education, 7-10 July, Caceras, Spain, 2005.

[10] March T., 2003 March T. The learning power of WebQuests. Educational Leadership. 2003; 61(4): 42-47.

[11] Samuel Ayobami Aina, Alaba Olaniyi Sofowora Aina SA, Sofowora AO. Perceived benefits and attitudes of student teachers to web-quest as a motivating, creative and inquiry-based learning tool in education. Higher Education Studies. 2013; 3(5): 29-35.

[12] S.L. Rubinstein, Fundamentals of General Psychology: a textbook. SPb., 2000.712 p.

[13] A.K. Markova, Formation of the motivation of learning: a book for the teacher. M., $1990.192 \mathrm{p}$.

[14] N. A. Pavlova, Motivation for the educational activities of students of a pedagogical university, Yaroslavl, 2005. $212 \mathrm{p}$.

[15] V.G. Katashev, Pedagogy of higher education. Kazan, 2005.395 p.

[16] O.V. Morozova, Motivational characteristics of educational activities of students. Innovation in science. Part II Novosibirsk, 2012.

[17] Dodge B. WebQuest Taskonomy: A Taxonomy of Tasks.1999. [Electronic resource]. - URL: http://webquest.org/sdsu/taskonomy.html

[18] I.N. Sokol, Classification of quests. Molody Vcheny. 2014. No. 6 (09). Pp. 138-140.

[19] A.A. Verbitsky, The development of student motivation in contextual learning. M., 2000.200 p.

[20] E.L.Deci, A.J. Schwartz, L. Sheinman, R.M. Ryan, An instrument to access adults' orientation toward control versus autonomy with children: Reflections on intrinsic motivation and perceived competence. Journal of Educational Psychology, 1981. V. 73. pp. 642-650.

[21] E. Halat, A good teaching technique: Webquests, The Clearing House, 2008a. 81(3), pp. 109-111.

[22] Paula Barnard-Ashton, Janine van der Linde, Alan Rothberg, Patricia McInerney First-year students' experience of a WebQuest to explore the University's online resources and virtual learning environment South African Journal of Occupational Therapy Aug, vol. 48 no. 2:3-11. 